\title{
НАНОСТРУКТУРИРОВАННЫЙ ФОТОСЕНСИБИЛИЗАТОР НА ОСНОВЕ ТЕТРАКАТИОННОГО ПРОИЗВОДНОГО БАКТЕРИОХЛОРИНА ДЛЯ АНТИБАКТЕРИАЛЬНОЙ ФОТОДИНАМИЧЕСКОЙ ТЕРАПИИ
}

Г. А. Меерович ${ }^{1,2}$, Е. В. Ахлюстина², И. Г. Тиганова ${ }^{3}$, Е. А. Макарова ${ }^{4}$, Н. И. Филипова ${ }^{3}$, И. Д. Романишкин ${ }^{1}$, Н. В. Алексеева ${ }^{3}$ Е. А. Лукьянец ${ }^{4}$, Ю. М. Романова ${ }^{3}$, В. Б. Лощенов ${ }^{1,2}$

Институт общей физики имени А. М. Прохорова РАН, Москва

2 Инженерно-физический институт биомедицины, Национальный исследовательский ядерный университет «МИФИ», Москва

${ }^{3}$ Национальный исследовательский центр эпидемиологии и микробиологии имени Н. Ф. Гамалеи, Москва

${ }^{4}$ Научно-исследовательский институт органических полупродуктов и красителей, Москва

Задача повышения эффективности антибактериальной ФДТ делает актуальными создание и исследование фотосенсибилизаторов (ФС) на основе поликатионных синтетических бактериохлоринов. Целью работы было изучить в широком диапазоне концентраций фотофизические и антибактериальные свойства наноструктурированного ФС на основе тетракатионного амфифильного производного синтетического бактериохлорина $3-\mathrm{Py}_{4} \mathrm{BCHp}_{4} \mathrm{Br}_{4}$. Наноструктурированную дисперсию ФС получили путем его солюбилизации в 4\%-м Kolliphor ELP. Исследование интенсивности и формы спектров поглощения и флуоресценции в диапазоне концентраций от 0,001 до 0,2 мМ продемонстрировало низкую агрегацию этого ФС во всем диапазоне и высокую эффективность фотодинамической инактивации грамположительных бактерий S. aureus и грамотрицательных бактерий P. aeruginosa и K. pneumoniae.

Ключевые слова: фотосенсибилизатор, катионный бактериохлорин, агрегация, наноструктурированная дисперсия, флуоресценция, антибактериальная фотодинамическая терапия

$\bowtie$ Для корреспонденции: Геннадий Александрович Меерович

ул. Вавилова, д. 38, г. Москва, 119991; meerovich@mail.ru

Статья получена: 31.08.2018 Статья принята к печати: 27.09.2018

DOI: $10.24075 /$ vrgmu.2018.087

\section{NANOSTRUCTURED PHOTOSENSITIZER BASED ON A TETRACATIONIC DERIVATIVE OF BACTERIOCHLORIN FOR ANTIBACTERIAL PHOTODYNAMIC THERAPY}

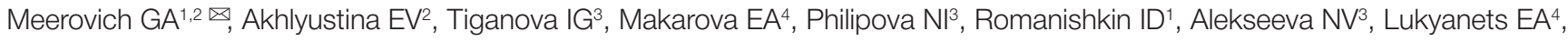
Romanova YuM ${ }^{3}$, Loschenov VB ${ }^{1,2}$

Prokhorov General Physics Institute of the Russian Academy of Sciences, Moscow

${ }^{2}$ Institute of engineering physics for biomedicine, National Research Nuclear University "MEPHI", Moscow

${ }^{3}$ Gamaleya National Research Center of Epidemiology and Microbiology, Moscow

${ }^{4}$ Organic Intermediates and Dyes Institute, Moscow

Making antibacterial PDT more effective is a task that calls for the development of photosensitizers (PS) based on polycationic synthetic bacteriochlorins and subsequent analysis of properties of such photosensitizers. This study aimed to explore photophysical and antibacterial properties of the nanostructured PS based on $3-\mathrm{Py}_{4} \mathrm{BSHp}_{4} \mathrm{Br}_{4}$, tetracationic amphiphilic derivative of synthetic bacteriochlorin. The PS was solubilized in a 4\% Kolliphor ELP to obtain its nanostructured dispersion. We researched the absorption and fluorescence spectra intensity and profiles, studying concentrations from 0.001 to $0.2 \mathrm{mM}$, and found that the aggregation level of the PS in question is low throughout the range investigated while the S. aureus (gram-positive) and $P$. aeruginosa and $K$. pneumoniae (gram-negative) PD inactivation effectiveness is high.

Keywords: photosensitizer, cationic bacteriochlorin, aggregation, nanostructured dispersion, fluorescence, antibacterial photodynamic therapy

$\triangle$ Correspondence should be addressed: Gennady A. Meerovich

Vavilova 38, Moscow, 119991; meerovich@mail.ru

Received: 31.08.2018 Accepted: 27.09.2018

DOI: $10.24075 /$ brsmu.2018.087

Антибактериальная фотодинамическая терапия (АФДТ) является перспективным способом лечения локальных инсицированных очагов, в частности хирургических и ожоговых ран, трофических и диабетических язв $[1,2]$. При АФДТ в отличие от антибиотикотерапии разрушение бактериальных клеток происходит без развития резистентности в ответ на лечение [3-6]. Большинство патогенных микроорганизмов, в том числе устойчивые к антибиотикам штаммы бактерий, восприимчиво к АФДТ [7].

В локальных инфицированных очагах, в частности инфицированных ранах, наиболее часто обнаруживаются 
грамположительные бактерии Staphylococcus aureus (S. aureus), грамотрицательные бактерии Pseudomonas aeruginosa ( $P$. aeruginosa) и Klebsiella pneumoniae (K. pneumoniae), штаммы которых могут обладать множественной антибиотикорезистентностью, приводить к переходу процессов в хроническое состояние и различным опасным последствиям для пациентов [8].

Грамположительные и грамотрицательные бактерии имеют принципиальные различия в своем строении и чувствительности к лекарственному воздействию. Клеточная стенка грамположительных бактерий не оказывает существенного влияния на проникновение в них большинства фотосенсибилизаторов (ФС). У грамотрицательных бактерий она обладает дополнительным структурным элементом - наружной мембраной толщиной 10-15 нм, имеющей гетерогенный состав (белки с пориновой функцией, липополисахаридные тримеры и липопротеины, создающие внешнюю псевдоповерхность плотно упакованных отрицательных зарядов) [9-11]. Такая система препятствует проникновению гуморальных защитных факторов организма и является причиной устойчивости ко многим лекарственным препаратам: через пориновые каналы диффундируют только относительно гидрофильные соединения с молекулярной массой ниже 700 Да, а при увеличении размеров и массы молекул вероятность их диффузии внутрь грамотрицательных бактерий снижается. С грамотрицательными бактериями эфффективно взаимодействуют только катионные ФС [10, 11]. Дополнительным преимуществом катионных ФС может быть возможность использования для сенсибилизации их высококонцентрированных водных композиций (растворов или нанодисперсий), поскольку кулоновское отталкивание молекул катионных бактериохлоринов может частично уменьшить их агрегацию [12], снижающую эффективность фотодинамических процессов.

При выборе ФС для АФДТ необходимо иметь в виду, что глубина очагов инфекционного поражения некоторыми бактериями, например P. aeruginosa, может достигать 12-15 мм [13], делая неэффективным применение как обычных аппликационных антибактериальных средств (растворов, мазей, гелей), так и ФС, проявляющих фототоксичность при возбуждении в видимом диапазоне спектра. Поэтому для надлежащего фотодинамического воздействия на такие очаги необходимо использовать для АФДТ ФС ближнего инфракрасного диапазона, возбуждение которых осуществляется в «спектральном окне прозрачности биологической ткани» (720-850 нм). В связи с этим в качестве ФС для АФДТ активно исследуют катионные производные бактериохлоринов. Исследования, проведенные на поликатионных производных синтетических бактериохлоринов с молекулярной массой 1500-1800 Да, показали, что эти ФС обеспечивают инактивацию как грамположительных бактерий S. aureus, так и грамотрицательных бактерий P. aeruginosa, однако значения минимальной бактерицидной концентрации при использовании этих ФС достаточно высоки (> 6 мкМ на S. aureus, около 25 мкM на $P$. aeruginosa) [14].

Задача повышения эффективности антибактериальной ФДТ делает актуальными создание и исследование ФС на основе поликатионных синтетических бактериохлоринов с уменьшенными размером молекулы и молекулярной массой. Целью работы было изучить в широком диапазоне концентраций фотофизические и антибактериальные свойства наноструктурированного ФС на основе тетракатионного амфиифильного производного синтетического бактериохлорина мезо-тетра(1-гептил-3-пиридил)бактериохлорина тетрабромида 3- $\mathrm{Py}_{4} \mathrm{BCHp}_{4} \mathrm{Br}_{4}$.

\section{МАТЕРИАЛЫ И МЕТОДЫ}

Тетракатионное амфифильное производное синтетического бактериохлорина - мезо-тетра(1-гептил-3-пиридил) бактериохлорина) тетрабромид 3- $\mathrm{Py}_{4} \mathrm{BCH}_{4} \mathrm{Br}_{4}$ - обладает меньшей степенью липофильности и меньшим радиусом молекулы по сравнению с производным, описанным ранее [14]. Оно было синтезировано алкилированием мезо-тетра(3-пиридил)бактериохлорина бромистым гептилом в нитрометане в инертной атмосфере. Наноструктурированную дисперсию 3-Ру ${ }_{4} \mathrm{BCHp}{ }_{4} \mathrm{Br}_{4}$ получили путем его солюбилизации в 4\%-й дисперсии Kolliphor ELP (BASF; Германия). Гидродинамический размер наночастиц, по результатам измерений на приборе Zetasizer Nano Series ZS 3600 (Malvern Panalitical; Великобритания), лежит в пределах 12-14 HM.

Поглощение ФС в диапазоне концентраций 0,001-0,1 мМ изучали на двухлучевом спектрофотометре Hitachi U-3410 (Hitachi; Япония), а спектрально-срлуоресцентные исследования проводили с использованием спектроанализатора ЛЭСА01-Биоспек (ООО БИОСПЕК; Россия). Флуоресценцию возбуждали лазерным излучением с длиной волны 532 нм, попадающей в $\mathrm{Q}_{2}$-полосу производного бактериохлорина. Для изучения особенностей формы спектральной полосы спектрально-фрлуоресцентные исследования ФС проводили в кюветах разной длины (1 мм и 10 мм), а спектральную интенсивность фрлуоресценции дополнительно нормировали на интенсивность флуоресценции в спектральном максимуме ее полосы (приводили спектральный максимум к 1). Это позволило при анализе спектров разделить изменения, связанные с перепоглощением и агрегацией.

Для измерения времени жизни люминесценции водных композиций исследуемых ФС использовали спектрометр с время-разрешающей регистрацией. Спектрометр включал в себя пикосекундный импульсный лазерный источник с оптоволоконным выходом Picosecond Light Pulser PLP-10 (Hamamatsu; Япония), генерирующий импульсное лазерное излучение с длиной волны 637 нм и длительностью импульса 65 пс, полихроматор Jarrell-Ash (Division of Fisher (о; США) с оптоволоконным входом и оптическим фильтром Semrock LD01-785/10-12.5 (Semrock Inc; CШA) на входе, который пропускал только спектральную область полосы люминесценции производных бактериохлоринов и минимизировал влияние сторонних засветок. Полученный сигнал аппроксимировали суммой нескольких экспонент.

Изучение фотоинактивации планктонных бактерий проводили на клинических изолятах $S$. aureus 15, $P$. aeruginosa 32, K. pneumoniae 1556. Бактерии выращивали в питательном бульоне LB или на 1\%-м агаре LB (Difco; CШA). Для планктонных культур определяли минимальную бактерицидную концентрацию (МБК) ФС в стандартных условиях: инкубация бактерий с ФС в течение 30 мин, плотность дозы облучения - 20 Дж/см². Исходный титр бактерий составляли $1 \cdot 10^{8} \mathrm{KOE} / \mathrm{M} л$ (колониеобразующих единиц в миллилитре). Использовали двукратные разведения ФС, начиная с 1 мМ. После инкубации бактериальную суспензию центрифугировали в течение 5 мин при 7000 об./мин на лабораторной центрифуге Eppendorf (Eppendorf; Германия), ФС удаляли, бактерии ресуспендировали в физиологическом растворе, суспензии каждой концентрации (а также контроль без ФС) разливали по 100 мкл в лунки двух 96-луночных 
плоскодонных планшетов. Один из них был предназначен для опьта с облучением, другой для контроля без облучения.

Для облучения использовали светодиодный источник СФД-М-760 (АНО «МИКЭЛ»; Россия) с длиной волны спектрального максимума 760 нм и полушириной спектральной полосы, равной примерно 35 нм. Плотность мощности составляла 22-25 мВт/см², длительность облучения - 20 мин. Для контроля плотности мощности использовали измеритель Coherent labmax (Coherent; США) с диафрагмой.

После облучения 50 мкл из каждой лунки высевали на чашки Петри с агаром LB, инкубировали в темноте при $37^{\circ} \mathrm{C}$ в течение 20 ч. Отмечали наименьшую концентрацию ФС, высев из которой не давал роста. Эту концентрацию принимали за МБК.

\section{РЕЗУЛЬТАТЫ}

Изучение зависимости поглощения 3- $\mathrm{Py}_{4} \mathrm{BCH}_{4} \mathrm{Br}_{4}$ от его концентрации в нанодисперсии проводили для оценки выраженности агрегационных процессов. Рабочая полоса поглощения 3- $\mathrm{Py}_{4} \mathrm{BCHp} \mathrm{Br}_{4}$ имеет узкий спектральный контур (полуширина составляет примерно 22 нм) с максимумом около 760 нм. Исследования показали, что в отличие от поликатионных фрталоцианинов признаки агрегации в спектрах поглощения дисперсии 3-Pу ${ }_{4} \mathrm{BCHp}_{4} \mathrm{Br}_{4}$ не выражены [15]: форма спектра поглощения не изменяется при увеличении концентрации; зависимость оптической плотности от молярной концентрации линейна (выполняется закон Бугера) и согласуется со значениями экстинкции, определенными при низких концентрациях (рис. 1).

Для подтверждения высказанного предположения о невысокой степени агрегации изучаемого ФС проводили спектрально-фрлуоресцентные исследования его нанодисперсии. Изучали форму и интенсивность спектров фллуоресценции, а также излучательное время жизни возбужденного состояния 3- $\mathrm{Py}_{4} \mathrm{BCHp}_{4} \mathrm{Br}_{4}$ при высоких и низких значениях концентрации.

Анализ приведенных спектров флуоресценции ФС показывает, что увеличение длины кюветы от 1 до 10 мм при низких (0,005 мМ) значениях концентрации не влияет на форму спектрального контура (рис. 2, спектры 1, 2), приводя только к незначительному (на 0,3 нм) сдвигу спектрального максимума из-за перепоглощения. При этом полоса флуоресценции остается узкой (27 нм).

При высоких (0,05 мМ) значениях концентрации, примерно соответствующих концентрации ФС в плазме крови через 1 ч после внутривенного введения, из-за перепоглощения происходит длинноволновое смещение спектрального максимума полосы фрлуоресценции, зависящее от длины кюветы (на 1,5 нм - в кювете длиной 1 мм и на 3,4 нм - в кювете длиной 10 мм). При этом увеличивается и полуширина полосы флуоресценции (в кювете 1 мм - на 1,1 нм, а в кювете 10 мм - на 4,3 нм),

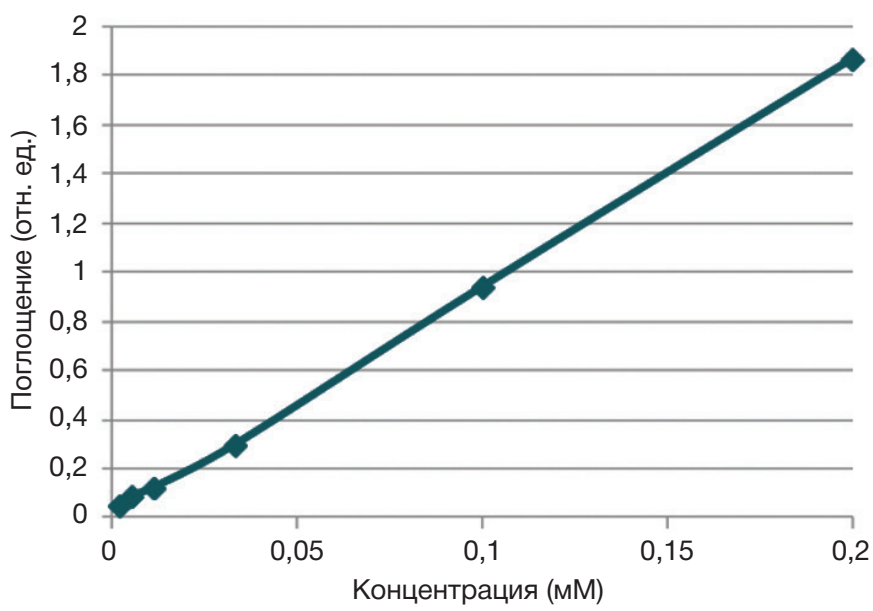

Рис. 1. Зависимость поглощения дисперсии 3- $\mathrm{Py}_{4} \mathrm{BCHp}_{4} \mathrm{Br}_{4}$ в 4\%-м Kolliphor ELP от ее концентрации

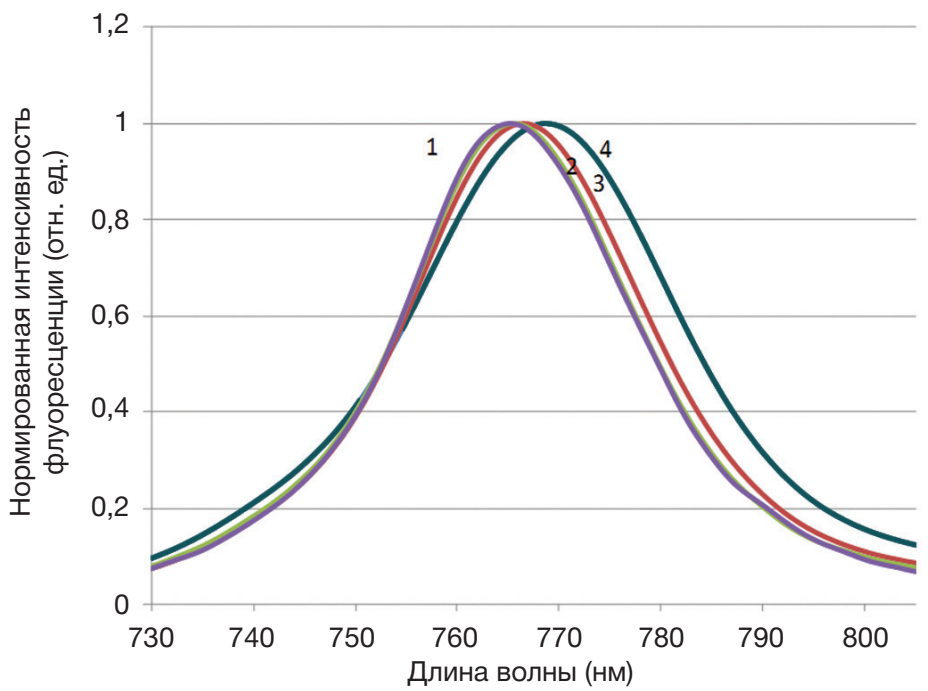

Рис. 2. Приведенные спектры флуоресценции дисперсий 3-Ру ВСНр, Вr, разной концентрации (спектры 1,2 - 0,005 мМ; спектры 3,4 - 0,05 мМ) при исследованиях в кюветах разной длины (спектры 1, 3 - 1 мм; спектры 2, 4 - 10 мм) 


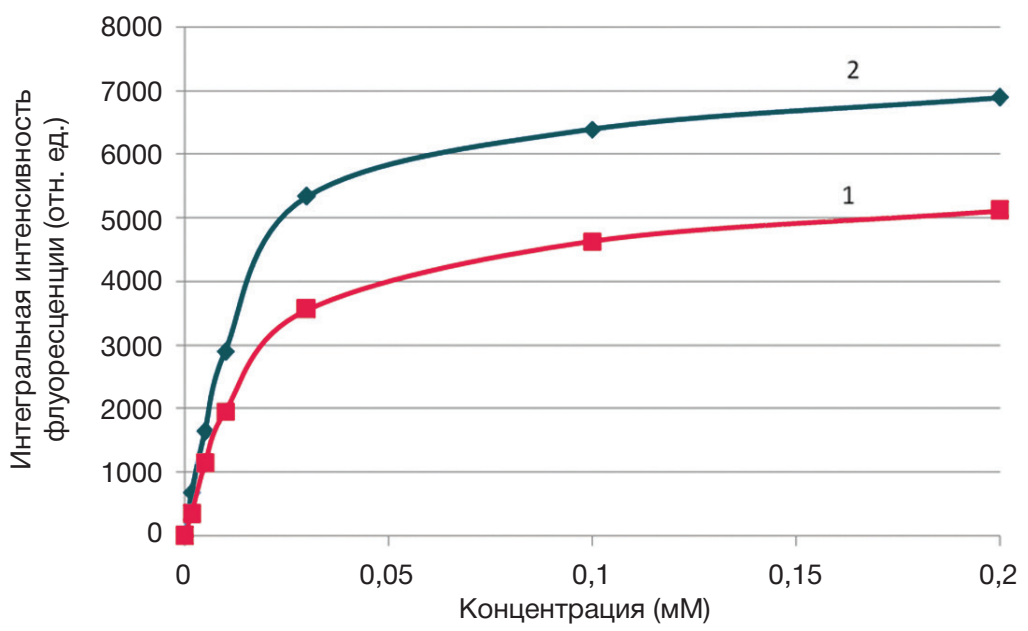

Рис. 3. Зависимость интегральной интенсивности флуоресценции водных композиций 3- $\mathrm{Py}_{4} \mathrm{BCHр}{ }_{4} \mathrm{Br}_{4}$ от их молярной концентрации: 1 - в воде; 2 в плазме крови

но форма спектрального контура не меняется, в нем не появляются дополнительные батохромно и гипсохромно сдвинутые пики.

Исследование излучательного времени жизни с использованием ранее описанного подхода [16] показало наличие двух компонент. Доминирующей при исследованиях в воде является компонента со средним значением времени жизни, равным 2,8 нс, доля которой составляет примерно 86\%. В плазме крови, где агрегация снижается, доминирующая компонента со средним значением времени жизни, равным около 2,9 нс, составляет почти 100\%.

Зависимость интегральной интенсивности флуоресценции дисперсии от концентрации ФС близка к линейной до 0,03 мМ (рис. 3), а при более высоких концентрациях становится сублинейной. Такая же зависимость наблюдается для композиции 3- $\mathrm{Py}_{4} \mathrm{BCHp}_{4} \mathrm{Br}_{4}$ в плазме крови. При этом форма кривых почти не изменяется, хотя интенсивность флуоресценции в плазме крови выше по сравнению с интенсивностью флуоресценции в воде в 1,3-1,4 раза.

Результаты определения МБK 3- $\mathrm{Py}_{4} \mathrm{BCHp}_{4} \mathrm{Br}_{4} \quad$ в стандартных условиях представлены в таблице (см. ниже).

\section{ОБСУЖДЕНИЕ}

Результаты исследования поглощения ФС свидетельствуют о невысокой степени их агрегации в изучаемом диапазоне концентраций [15], поскольку во всем диапазоне его концентраций форма и полуширина спектра полосы поглощения не изменяются, а поглощение линейно зависит от концентрации.

Анализ особенностей изменения формы спектральной полосы флуоресценции при увеличении концентрации и длины кюветы позволяет предположить, что наблюдаемые явления, происходящие при высокой концентрации изучаемого ФС, связаны преимущественно с перепоглощением; при этом имеет место и агрегация, но вклад ее незначителен. Об этом же свидетельствуют результаты изучения излучательного времени жизни возбужденного состояния ФС на основе 3- $\mathrm{Py}_{4} \mathrm{BCHp}_{4} \mathrm{Br}_{4}$ и зависимости интенсивности флуоресценции от концентрации 3- $\mathrm{Py}_{4} \mathrm{BCH}_{4} \mathrm{Br}_{4}$ в дисперсии, особенно в плазме крови [17-21].

Эти данные позволяют сделать вывод, что эффективность фотодинамических процессов при высоких концентрациях 3- $\mathrm{Py}_{4} \mathrm{BCHp} \mathrm{Br}_{4}$ не будет снижаться и дает возможность использовать нанодисперсии 3-Ру ${ }_{4} \mathrm{BCH}_{4} \mathrm{Br}_{4}$ с такими концентрациями для сенсибилизации при АФДТ.

По сравнению с ФС на основе катионных бактериохлоринов, описанных ранее [14], 3- $\mathrm{Py}_{4} \mathrm{BCHp}_{4} \mathrm{Br}_{4}$ имеет значительно более низкие значения МБК для грамположительных бактерий S. aureus и грамотрицательных бактерий $P$. aeruginosa в планктонном состоянии. Низкие значения МБК получены также для грамотрицательных бактерий K. pneumoniae.

\section{ВЫВОДЫ}

Результаты исследований показывают, что исследуемый тетракатионный ФС на основе синтетического амфифильного производного бактериохлорина 3- $\mathrm{Py}_{4} \mathrm{BCH}_{4} \mathrm{Br}_{4}$ с уменьшенными размером молекулы и молекулярной массой обладает высокой эффективностью фотодинамической инактивации грамположительных бактерий S. aureus и грамотрицательных бактерий $P$. aeruginosa и K. pneumoniae. Исследования фотофизических свойств ФС в широком диапазоне концентраций продемонстрировали его низкую агрегацию в воде и плазме крови. Результаты исследований позволяют сделать вывод, что ФС на основе наноструктурированной формы 3- $\mathrm{Py}_{4} \mathrm{BCH} \mathrm{H}_{4} \mathrm{Br}_{4}$ перспективен для фотодинамического лечения локальных инфицированных очагов, вызванных грамположительными и грамотрицательными бактериями.

Таблица. Значения МБК для 3-Ру $\mathrm{BCHp}_{4} \mathrm{Br}_{4}$ в стандартных условиях (время инкубации - 0,5 4, доза облучения - 20 Дж/см²)

\begin{tabular}{|c|c|c|c|}
\hline Вид бактерий & S. aureus & P. aeruginosa & K. pneumoniae \\
\hline Значения МБК, МКМ & 0,2 & 6,2 & 3,1 \\
\hline
\end{tabular}




\section{Литература}

1. Park YS, Lee HB, Chin S et al. Acquisition of extensive drugresistant $P$ seudomonas aeruginosa among hospitalized patients: risk factors and resistance mechanisms to carbapenems. Hosp Infect. 2011; 79 (1): 54-8. DOI: 10.1016/j.jhin.2011.05.014.

2. Bertoloni G, Rossi F, Valduga G, Jori et al. Photosensitising activity of water- and lipid-soluble phthalocyanines on prokaryotic and eukaryotic microbial cells. Microbios. 1992; 71 (286): 33-46.

3. Nakonieczna J, Michta E, Rybicka M et al. Superoxide dismutase is upregulated in Staphylococcus aureus following protoporphyrin-mediated photodynamic inactivation and does not directly influence the response to photodynamic treatment. BMC Microbiol. 2010; (10): 323. https://DOl.org/10.1186/14712180-10-323.

4. Tavares A, Carvalho CMB, Faustino MA et al. Antimicrobial photodynamic therapy: study of bacterial recovery viability and potential development of resistance after treatment. Marine Drugs. 2010; 8 (1): 91-105. DOI: 10.3390/md8010091.

5. Hamblin MR, Hasan T. Photodynamic therapy: a new antimicrobial approach to infectious disease. Photochem Photobiol Sci. 2004; 3 (5): 436-50.

6. Vera DM, Haynes $\mathrm{MH}$, Ball $\mathrm{AR}$ et al. Strategies to potentiate antimicrobial photoinactivation by overcoming resistant phenotypes. Photochem Photobiol. 2012; 88 (3): 499-511. DOI: 10.1111/j.1751-1097.2012.01087.x.

7. Maisch T. Resistance in antimicrobial photodynamic inactivation of bacteria. Photochem Photobiol. 2015; 14 (8): 1518-26. DOl: 10.1039/c5pp00037h

8. Almeida A, Cunha A, Faustino MAF et al. Porphyrins as antimicrobial photosensitizing agents. In: Photodynamic Inactivation of Microbial Pathogens: Medical and Environmental Applications. Hamblin MR, Jori G, editors. London: RSC Publishing, 2011; p. 83-160.

9. Wainwright M. Photodynamic antimicrobial chemotherapy. Antimicrob Chemother. 1998; 42 (1): 13-28.

10. Friedrich CL, Moyles D, Beveridge TJ, Hancock RE. Antibacterial action of structurally diverse cationic peptides on Gram-positive bacteria. Antimicrob Agents Chemother. 2000; 44 (8): 2086-92.

11. Nikaido $H$. Prevention of drug access to bacterial targets: Permeability barrier and active efflux. Science. 1994; 264 (5157): 382-8.

12. Moan J. Photochemistry and Photobiology. The photochemical yield of singlet oxygen from porphyrins in different states of aggregation. 1984; (39): 445-9. Available from: https://DOI. org/10.1111/j.1751-1097.1984.tb03873.x.

\section{References}

1. Park YS, Lee HB, Chin S et al. Acquisition of extensive drugresistant $P$ seudomonas aeruginosa among hospitalized patients: risk factors and resistance mechanisms to carbapenems. Hosp Infect. 2011; 79 (1): 54-8. DOI: 10.1016/j.jhin.2011.05.014.

2. Bertoloni G, Rossi F, Valduga G, Jori et al. Photosensitising activity of water- and lipid-soluble phthalocyanines on prokaryotic and eukaryotic microbial cells. Microbios. 1992; 71 (286): 33-46.

3. Nakonieczna J, Michta E, Rybicka M et al. Superoxide dismutase is upregulated in Staphylococcus aureus following protoporphyrin-mediated photodynamic inactivation and does not directly influence the response to photodynamic treatment. BMC Microbiol. 2010; (10): 323. https://DOl.org/10.1186/14712180-10-323.

4. Tavares A, Carvalho CMB, Faustino MA et al. Antimicrobial photodynamic therapy: study of bacterial recovery viability and potential development of resistance after treatment. Marine Drugs. 2010; 8 (1): 91-105. DOI: 10.3390/md8010091.

5. Hamblin MR, Hasan T. Photodynamic therapy: a new antimicrobial approach to infectious disease. Photochem Photobiol Sci. 2004; 3 (5): 436-50

6. Vera DM, Haynes $\mathrm{MH}$, Ball $\mathrm{AR}$ et al. Strategies to potentiate antimicrobial photoinactivation by overcoming resistant phenotypes. Photochem Photobiol. 2012; 88 (3): 499-511. DOl: 10.1111/j.1751-1097.2012.01087.x.
13. Bjarnsholt Th, Jensen $\mathrm{PO}$, Moser C, Hoiby N. Biofilm infections. Heidelberg: Springer, 2011.

14. Тиганова И. Г., Макарова Е. А., Меерович Г. А., Алексеева Н. В., Толордава Э. Р., Жижимова Ю. С. и др. Фотодинамическая инактивация патогенных бактерий в биопленках с использованием новых синтетических производных бактериохлорина. Biomedical Photonics. 2017; 6 (4): 27-36. Доступно по ссылке: https://DOl.org/10.24931/2413-94322017-6-4-27-36

15. Макаров Д. А., Кузнецова Н. А., Южакова О. А., Савина Л. П., Калия О. Л., Лукьянец Е. А. и др. Поликатионные фталоцианины цинка и алюминия: синтез, влияние степени замещения на физико-химические свойства и фотодинамическую активность в водной среде. Журнал физической химии. 2009; 83 (6): 1183-90.

16. Быстров Ф. Г., Макаров В. И., Поминова Д. В., Рябова А. В., Лощенов В. Б. Исследование кинетики затухания фотолюминесценции молекулярных нанокристаллов фталоцианина алюминия при взаимодействии с иммунокомпетентными клетками. Biomedical Photonics. 2016; 5 (1): 3-8. Доступно по ссылке: https://DOl.org/10.24931/24139432-2016-5-1-3-8.

17. Juzenas P, Juzeniene A, Rotomskis R, Moan J. Spectroscopic evidence of monomeric aluminium phthalocyanine tetrasulphonate in aqueous solutions. Journal of Photochemistry and Photobiology B: Biology. 2004; 75 (1-2): 107-10. DOl: 10.1016/j.jphotobiol. 2004.05.011.

18. Dhami S, Phillips D. Comparison of the photophysics of an aggregating and non-aggregating aluminium phthalocyanine system incorporated into unilamellar vesicles. Journal of Photochemistry and Photobiology A: Chemistry. 1996; 100 (1-3): 77-84.

19. Reddi E, Jori G. Reviews of Chemical Intermediates. 1988; (10): 241-68. Available from: https://DOI.org/10.1007/BF03155995

20. Tominaga TT, Yusbmanov VE, Borissevitch IE, Imasato $H$, Tabak M. Aggregation phenomena in the complexes of iron tetraphenylporphine sulfonate with bovine serum albumin. Journal of Inorganic Biochemistry. 1997; (65): 235-44.

21. Changenet-Barret P, Gustavsson T, Markovitsi D, Manet I, Monti S. Unravelling molecular mechanisms in the fluorescence spectra of doxorubicin in aqueous solution by femtosecond fluorescence spectroscopy. Physical Chemistry Chemical Physics. 2013; 15 (8): $2937-44$

7. Maisch T. Resistance in antimicrobial photodynamic inactivation of bacteria. Photochem Photobiol. 2015; 14 (8): 1518-26. DOI: 10.1039/c5pp00037h

8. Almeida A, Cunha A, Faustino MAF et al. Porphyrins as antimicrobial photosensitizing agents. In: Photodynamic Inactivation of Microbial Pathogens: Medical and Environmental Applications. Hamblin MR, Jori G, editors. London: RSC Publishing, 2011; p. 83-160.

9. Wainwright M. Photodynamic antimicrobial chemotherapy. Antimicrob Chemother. 1998; 42 (1): 13-28.

10. Friedrich CL, Moyles D, Beveridge TJ, Hancock RE. Antibacterial action of structurally diverse cationic peptides on Gram-positive bacteria. Antimicrob Agents Chemother. 2000; 44 (8): 2086-92.

11. Nikaido $H$. Prevention of drug access to bacterial targets: Permeability barrier and active efflux. Science. 1994; 264 (5157): 382-8.

12. Moan J. Photochemistry and Photobiology. The photochemical yield of singlet oxygen from porphyrins in different states of aggregation. 1984; (39): 445-9. Available from: https://DOI. org/10.1111/j.1751-1097.1984.tb03873.x

13. Bjarnsholt Th, Jensen PO, Moser C, Hoiby N. Biofilm infections. Heidelberg: Springer, 2011.

14. Tiganova IG, Makarova EA, Meerovich GA, Alekseeva NV, Tolordava ER, Zhizhimova YS et al. Photodynamic inactivation of pathogenic bacteria in biofilms using new synthetic bacteriochlorin 
derivatives. Biomedical Photonics. 2017; 6 (4): 27-36. Russian. Available from: https://DOl.org/10.24931/2413-9432-2017-6-4-27-36.

15. Makarov DA, Kuznetsova NA, Yuzhakova OA, Savina LP, Kaliya OL, Lukyanets EA et al. Effects of the degree of substitution on the physicochemical properties and photodynamic activity of zinc and aluminum phthalocyanine polycations. Russian Journal of Physical Chemistry A. 2009; 83 (6): 1044-50.

16. Bystrov FG, Makarov VI, Pominova DV, Ryabova AV, Loschenov VB. Analysis of photoluminescence decay kinetics of aluminum phthalocyanine nanoparticles interacting with immune cells. Biomedical Photonics. 2016; 5 (1): 3-8. Russian. Available from: https://DOl.org/10.24931/2413-9432-2016-5-1-3-8.

17. Juzenas $P$, Juzeniene $A$, Rotomskis R, Moan J. Spectroscopic evidence of monomeric aluminium phthalocyanine tetrasulphonate in aqueous solutions. Journal of Photochemistry and Photobiology B: Biology. 2004; 75 (1-2): 107-10. DOI: 10.1016/j.jphotobiol. 2004.05.011.
18. Dhami S, Phillips D. Comparison of the photophysics of an aggregating and non-aggregating aluminium phthalocyanine system incorporated into unilamellar vesicles. Journal of Photochemistry and Photobiology A: Chemistry. 1996; 100 (1-3): 77-84.

19. Reddi E, Jori G. Reviews of Chemical Intermediates. 1988; (10): 241-68. Available from: https://DOl.org/10.1007/BF03155995

20. Tominaga TT, Yusbmanov VE, Borissevitch IE, Imasato $H$, Tabak M. Aggregation phenomena in the complexes of iron tetraphenylporphine sulfonate with bovine serum albumin. Journal of Inorganic Biochemistry. 1997; (65): 235-44.

21. Changenet-Barret P, Gustavsson T, Markovitsi D, Manet I, Monti S. Unravelling molecular mechanisms in the fluorescence spectra of doxorubicin in aqueous solution by femtosecond fluorescence spectroscopy. Physical Chemistry Chemical Physics. 2013; 15 (8): 2937-44. 